\title{
The knees and ankles in sport and veteran military parachutists
}

\author{
C. F. MURRAY-LESLIE, D. J. LINTOTT, AND V. WRIGHT
}

From the Rheumatism Research Unit, University of Leeds, and Department of Diagnostic Radiology, General Infirmary at Leeds

SUMMARY 112 actively parachuting sport (free fall) parachutists with more than 200 descents each and 109 veteran military parachutists no longer active returned a postal questionnaire about their parachuting activities, injuries, and current and past musculoskeletal symptoms. A high frequency of fractures and injuries was reported by each group, both in relation to parachuting and to other activities. 58 sport parachutists aged 23 to 57 years (mean 33.3 years) had weight-bearing anteroposterior and lateral radiographs taken of each knee. These showed a prevalence of radiological osteoarthrosis of $10.4 \%$ which was mild in degree in all but one knee in one subject. 46 ex-military parachutists aged 50 to 70 years (mean 55.2 years) had weight-bearing anteroposterior radiographs taken of both knees and showed a prevalence of radiological osteroarthrosis of $41 \cdot 3 \%$. Moderate and severe changes were found in $10.9 \%$. In both groups of parachutists six of the eight knee joints showing either moderate or severe radiological osteroathrosis had been subjected to a previous meniscectomy.

Forty ex-military parachutists had anteroposterior radiographs of the ankles (talotibial articulation) and showed a prevalence of osteoarthrosis of $17 \cdot 5 \%$, with the majority showing mild changes. There was a poor correlation between radiological osteoarthrosis, ankle symptoms, and previous fractures.

With the reservation that the great majority of the sport group are still young $(95 \%$ aged $<50$ years), it is concluded that parachutists as a group do not show an increased prevalence of radiological osteoarthrosis of the knee or ankle.

It is only in the last 36 years that large numbers of parachute descents have taken place in the United Kingdom. Large scale military parachuting began in 1940 (Newnham, 1974), and the first world parachuting championship held in 1951 marked the advent of parachuting as a sport (Hearn, 1976).

The frequency of parachuting injuries requiring hospital treatment has been given as 0.25 per 100 jumps over a 5-year period in the British Army by Kirby (1974), and as $0 \cdot 13$ per 100 jumps over 3 years in one civilian sport parachuting centre by Quinlan (1975). The type of injuries and their relative frequency in military parachuting have been determined by Essex-Lopresti (1946), Ciccone and Richman (1948), Kiel (1965), and Kirby (1974).

Despite much information on the acute injuries

Accepted for publication November 26, 1976

Correspondence to Dr. C. Murray-Leslie, Dept. of Rheumatology and Rehabilitation, Derbyshire Royal Infirmary, London Road, Derby DE1 2QY. received while parachuting, no adequate study of the long-term effect of parachuting on the bones and joints has been made. Essex-Lopresti (1946) and Kirby (1974) stated without giving figures that osteoarthrosis of the knees and ankles of parachutists may occur after many descents. Ciccone and Richman (1948), also without giving figures, stated that certain cases of multiple ankle fractures may lead to permanent arthritic disability. The department in Leeds has a particular interest in the aetiological factors of osteoarthrosis from clinical and bioengineering viewpoints. This paper, therefore, describes a study to determine the long-term effects of parachuting on the knees and ankles.

\section{Material and methods}

The names and addresses of 125 of the most experienced sport (free fall) parachutists who had carried out from 200 to nearly 3000 descents each 
were obtained from the British Parachute Association. Between August 1973 and March 1974 each was sent a postal questionnaire relating to their medical history and parachuting experience. Those who agreed underwent a radiological examination of both knees (anteroposterior views with subject weight bearing, and lateral views, all with gonadal screening).

The names and addresses of 368 ex-military parachutists in Leeds and Bradford who were no longer parachuting but who had served in the Parachute Regiment at various times since its formation during the second world war were obtained from the Parachute Regimental Association. In 1975 each was sent a postal questionnaire similar to the one sent to the sport parachutists. In addition the names and addresses of 10 ex-RAF parachute instructors who had served in the second world war were supplied by the Canopy Club and these were also contacted by postal questionnaire. All military parachutists who returned questionnaires and who were aged 50 years or over at the time of the survey were invited to undergo a radiological examination of the knees (anteroposterior, weight bearing) and ankles (anteroposterior views of the talotibial articulation only).

\section{RADIOLOGICAL METHODS}

All radiographs from both groups were read by D.J.L. in randomized sequence and in ignorance of the history or identity of the subjects. In both groups the tibiofemoral articulation was assessed for osteoarthrosis in respect of both osteophytosis and joint-space narrowing using 5 grades of severity $(0=$ normal, $1=$ doubtful, $2=$ mild, $3=$ moderate, $4=$ severe). In cases where narrowing of the tibiofemoral joint space was suspected, direct measurements were made of the medial and lateral compartments of each knee. Joint-space narrowing was considered to be present if either the medial or lateral compartment measured $4 \mathrm{~mm}$ or less at its midpoint, or a compartment was less than half the width of the other compartment of the same knee, or less than half the corresponding compartment of the opposite knee (Ahlback, 1968; Adams, 1973).

The patellofemoral joints of the sport parachutists and the talotibial joints of the veterans were assessed according to the 5 grades of severity $(0=$ normal, $1=$ doubtful, $2=$ mild, $3=$ moderate, $4=$ severe).

\section{Results}

QUESTIONNAIRE DATA

Completed questionnaires were returned by 112 sport parachutists (102 men, 10 women) aged 23 to 57 years (mean age 29.2 years), and 109 veteran military parachutists (99 ex-Army and 10 ex-RAF instructors) aged 28 to 70 (mean age 478 years).

\section{SPORT PARACHUTISTS}

These were very experienced parachutists, each with a large number of descents (mean 778 , range $200-\frac{\text { s }}{7}$ 2966) performed over relatively few years. $70 \%$ were qualified sport parachute instructors, $55 \%$ had had some experience of military parachuting $\overrightarrow{0}$ and $30 \%$ were in the armed forces at the time of the study. The frequency of fractures and knee andw ankle soft tissue injuries occurring during parachut ing and at other times is given in Table $1.52(42 \%$ individuals from this group had sustained at leas one fracture while parachuting. The heights and weights of the group sustaining lower limb and spinal fractures were not significantly different from those not sustaining such fractures.

Despite the frequency of soft tissue knee and anklesymptoms in the group, the questionnaires indicate that recurrent or persistent ankle $(1.8 \%)$ and kne $(7 \cdot 1 \%)$ symptoms were not common. $12\left(10 \cdot 7 \%{ }^{2}\right.$ parachutists had required hospital treatment fore knee injuries at some time and $3(2.6 \%)$, one of whom had radiology in this survey, had requiredmeniscectomy with or without repair of the collatera? or cruciate ligaments.

EX-MILITARY PARACHUTISTS

As a group these men had made far fewer descents (mean 236, range 7-700) with the exception of the

Table 1 Comparison of fractures and knee and ankle injuries occurring during parachuting and while not parachuting in 112 sport and 109 ex-military parachutists

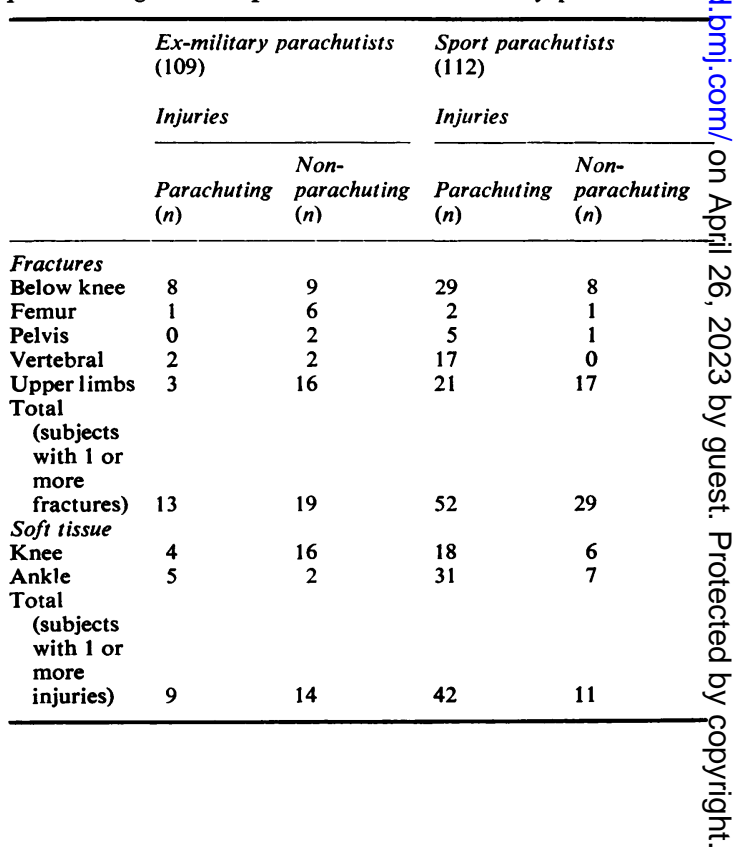


ex-RAF instructors (mean 659, range 200-1600) and had carried out their parachute jumps longer ago than their sport counterparts. They were also, with a few exceptions, a much older group. The frequency of the fractures and knee and ankle injuries occurring during parachuting and at other times is given in Table 1 . In all, $13(11.9 \%)$ of this group had sustained at least one fracture while parachuting. The heights and weights of those sustaining lower limb and spinal fractures was not significantly different from those not sustaining such fractures. Ankle symptoms were present at the time of the survey in 11 subjects $(10.1 \%)$ (pain in 8 , swelling in 2 , and feelings of instability in 1). In only 2 cases were those symptoms other than mild and in only one case were they related to a previous fracture. Knee symptoms were present at the time of the survey in 19 subjects $(17 \%)$ and consisted of pain in 16 subjects and swelling in 3 . In 4 subjects pain was described as moderate or severe. 9 subjects had received hospital treatment for knee symptoms and 4 had undergone meniscectomy ( 3 of the 4 subjects with a history of previous meniscectomy had radiological examinations in this survey).

As these men were no longer parachuting they were asked if they had any sumptoms that they considered were attributable to parachuting. Of the $18(16.5 \%)$ who replied in the affirmative, 6 specified back pain, 2 neck pain, 4 ankle symptoms, 3 knee symptoms, and 3 pain at an old fracture site (femur, elbow, shoulder).

\section{RADIOLOGICAL FINDINGS}

Radiological examinations were carried out on $\mathbf{5 8}$ $(69.8 \%)$ of the 83 sport parachutists who were

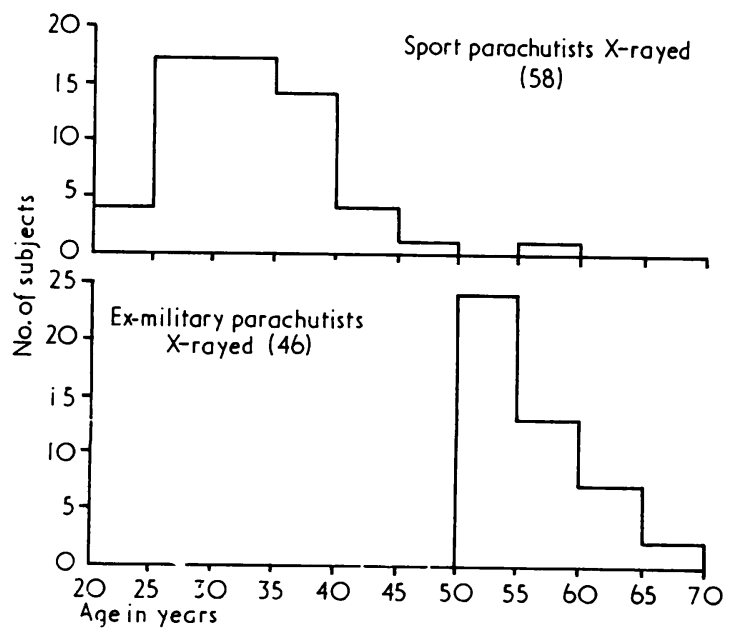

Fig. 1 Comparison of the age distribution in those sport and ex-military parachutists $\mathrm{x}$-rayed in survey. invited and $46(73 \%)$ of the 63 ex-military parachutists aged 50 years or over. The age distribution and parachuting experience of those $x$-rayed are shown in Figs. 1-3.

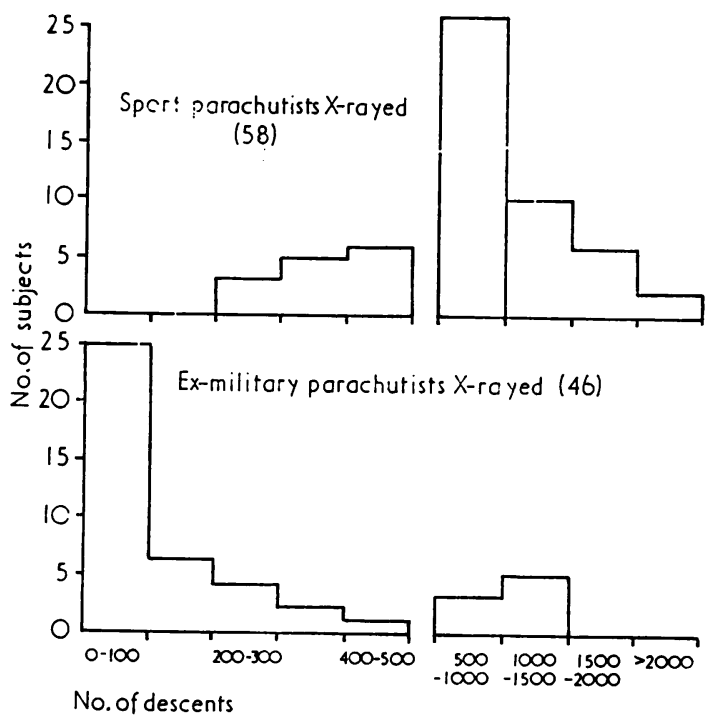

Fig. 2 Comparison of the number of descents in those sport and ex-military parachutists $\mathrm{x}$-rayed in survey.

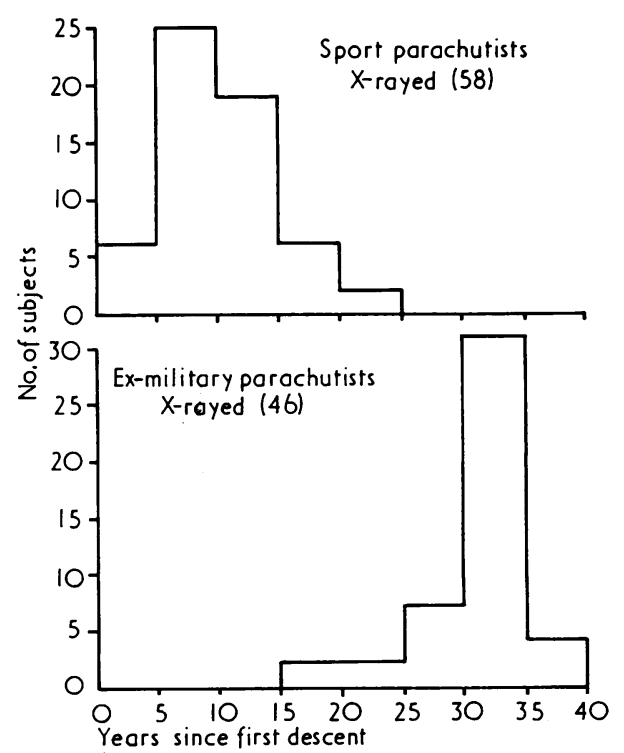

Fig. 3 The length of time which elapsed between the first descent and this survey in the sport and ex-military parachutists $\mathrm{x}$-rayed. 
Table 2 Prevalence of radiological osteoarthrosis of the knee in 58 sport and 46 ex-military parachutists

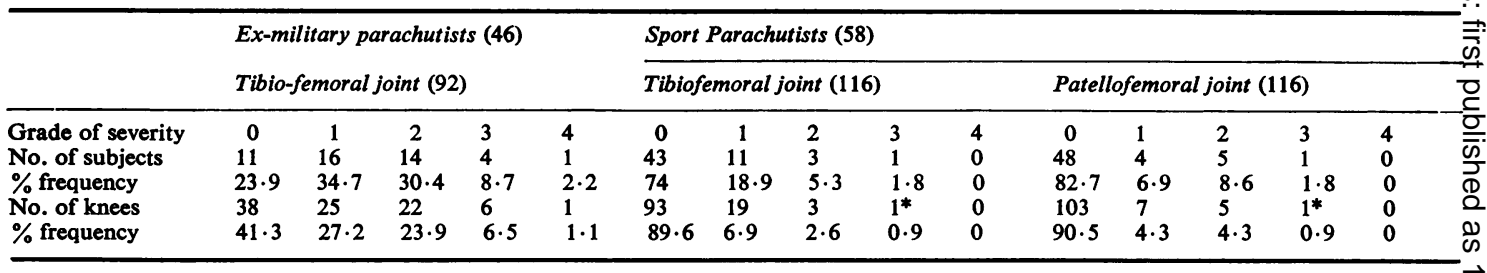

Note: The grades of osteoarthrosis shown (0-4, normal-severe) are the more severe of the two separate grades given for osteophytosis and joint $\overrightarrow{0}$ space narrowing for each joint assessed.

* Same knee.

Table 3 Details of parachutists showing an association between radiological osteoarthrosis $(O A)$ of the knee and previous meniscectomy

\begin{tabular}{|c|c|c|c|c|c|c|}
\hline Parachutist & $\begin{array}{l}\text { Age } \\
\text { (yedrs) }\end{array}$ & Knee & Grade of $O A$ & $\begin{array}{l}\text { Years since } \\
\text { meniscectomy }\end{array}$ & $\begin{array}{l}\text { Cause of } \\
\text { meniscal injury }\end{array}$ & $\begin{array}{l}\text { Present symptoms } \\
\text { and severity }\end{array}$ \\
\hline \multicolumn{7}{|l|}{ Ex-military } \\
\hline 1 & 62 & $\mathbf{R}$ & $\begin{array}{l}3 \\
2\end{array}$ & 41 & $\begin{array}{l}\text { Rugby } \\
\text { Rugby }\end{array}$ & Yes (moderate) \\
\hline 2 & 53 & $\begin{array}{l}\mathbf{R} \\
\mathbf{L}\end{array}$ & $\begin{array}{l}3 \\
3\end{array}$ & $\begin{array}{l}22 \\
27\end{array}$ & $\begin{array}{l}\text { Soccer } \\
\text { Parachute training }\end{array}$ & $\begin{array}{l}\text { No } \\
\text { No }\end{array}$ \\
\hline 3 & 50 & $\begin{array}{l}\mathbf{R} \\
\mathbf{L}\end{array}$ & $\begin{array}{l}3 \\
3\end{array}$ & 12 & $\begin{array}{l}\text { Soccer } \\
\text { Soccer }\end{array}$ & $\begin{array}{l}\text { Yes (severe) } \\
\text { Yes (severe) }\end{array}$ \\
\hline \multicolumn{7}{|l|}{ Sport } \\
\hline 4 & 32 & $\mathbf{R}$ & 3 & 10 & Soccer & Yes (moderate) \\
\hline
\end{tabular}

\section{Knees}

The prevalence of osteoarthrosis of the knee for each radiological projection for both groups of parachutists is shown in Table 2. The overall prevalence of radiological osteoarthrosis (grade 2 to 4 ) was $10.4 \%$ in the sport and $41.3 \%$ in the ex-military group, with most subjects showing only mild changes.

Taking both groups of parachutists together moderate (grade 3) or severe (grade 4) osteoarthrosis was found in eight knees in 6 subjects, and in six knees (all grade 3 ) in 4 subjects it was found to be related to a previous meniscectomy (Table 3 ). In fact, in every knee where a meniscus had been removed and which had been $x$-rayed, definite radiological changes of osteoarthrosis were present (moderate changes in 6, mild in 1). Symptoms were present in $75 \%$ of the knees from both groups of parachutists which showed moderate or severe radiological changes (grades 3 and 4 ) and $30 \%$ of the knees which showed mild changes.

\section{Ankles}

The prevalence of radiological osteoarthrosis in the ankles of 40 ex-military parachutists is shown in Table 4. Some degree of radiological osteoarthrosis (grades 2 to 3 ) was found in nine ankles in 7 subjects $(17.5 \%)$, with seven ankles in 5 subjects $(12.5 \%)$ showing only mild changes. Four of the nine ankles showing radiological osteoarthrosis were symptomatic and no ankle with osteoarthrosis had been the site of previous fracture.
Table 4 Prevalence of radiological osteoarthrosis $(O A)$ of the ankle (talotibial articulation, anteroposterior projection) in 40 ex-military parachutists

Ex-military parachutists (79 ankles in 40 subjects, aged over 50 years

\begin{tabular}{|c|c|c|}
\hline Grade of severity $O A$ & No. of ankles & No. of subje \\
\hline $\begin{array}{l}\text { Grade } 0 \text { (normal) } \\
\text { Grade } 1 \text { (doubtful) } \\
\text { Grade } 2 \text { (mild) } \\
\text { Grade } 3 \text { (moderate) }\end{array}$ & $\begin{array}{l}64(81.0 \%) \\
6(7.6 \%) \\
7(8.9 \%) \\
2(2.5 \%)\end{array}$ & $\begin{array}{l}30(75 \%) \\
3(7.5 \%) \\
5(12 \cdot 5 \%) \\
2(5 \%)\end{array}$ \\
\hline
\end{tabular}

\section{Discussion}

The excellent completion rate $(90 \%)$ of the question naire survey in sport parachutists was probably due to the fact that the majority of these were know personally to one of the authors (C.F.M-L.). In the case of the ex-military parachutists, many of the addresses supplied by the local branches of the Parachute Regimental Association no longer existed due to extensive demolition of housing in Leeds ang Bradford, but when incorrect addresses and deaths were allowed for, $60 \%$ of those approached returnef questionnaires.

The two groups of parachutists differed consideriably in age, numbers of descents, and length of parachuting experience (Figs. 1 to 3). Although none of the ex-military group was currently parachutin ? 8 had had to terminate their parachuting caree through injury, often war wounds, and through 
knee symptoms. All the sport parachutists, however, were still active.

The results show that both groups of parachutists studied have suffered many injuries (Table 1). The sport parachutists showed particularly high injury figures, which probably reflects their greater number of descents and greater frequency of parachuting with greater opportunity for injury, but also in some cases low standards of physical fitness, poor handling of sophisticated parachutes, and jumping in unsuitable weather conditions. Knee injuries were reported commonly by both groups (Table 1), but in sport parachutists they occurred more commonly while parachuting, in contrast to the veteran military group where knee injuries had occurred more frequently playing soccer or rugby football. The difference may be explained by the fewer descents made by the military parachutists with their meticulous attention to landing techniques or the frequency with which this group were involved in contact sports. A further factor may be the high frequency with which the sport parachutists took part in precision parachuting competitions where caution and the usual 'military legs together' landing technique is abandoned in the interest of greater accuracy.

However, the questionnaires also showed that recurrent or persistent knee or ankle symptoms were not a common problem in either group of parachutists. The fractures and injuries received while not parachuting were similar for both groups, suggesting a similar active mode of life and a similar liability to injury (Table 1).

The frequency of radiological osteoarthrosis of the knee (tibiofemoral and patellofemoral) in sport parachutists was low and in those which did show changes all but one were mild. In this group the overall frequency of osteoarthrosis (including mild grades) of $10.4 \%$ is similar to the figure of $10.6 \%$ found at Leeds by Adams (1973), using similar radiological criteria for 51 professional footballers and 15 ex-professional footballers. In the 46 exmilitary parachutists, all of whom were aged 50 years or more, the frequency of mild osteoarthrosis of the knee (grade 2 ) was $30.4 \%$, and moderate and severe osteoarthrosis of the knee (grades 3 and 4) was $10.9 \%$ when the tibiofemoral compartments only were studied. This compares with frequencies of $18.7 \%$ and $11.1 \%$ using similar grading methods (Jeffrey et al., 1963) for the same two grades of severity among men aged 55 to 64 years in a population survey in the town of Leigh (Kellgren and Lawrence, 1958).

The association found between the severer grades of osteoarthrosis of the knee and a history of meniscectomy is of interest in view of the findings of Jackson (1958). In the parachutists it was not usually possible to compare the postmeniscectomy knee with a nonoperated knee in the same subject, as in 4 out of the 5 subjects menisci had been removed bilaterally.

Radiological osteoarthrosis of the talotibial articulation (anteroposterior view only) was mild, very infrequent, and not associated with past fracture. However, since it would be natural to expect that osteoarthrosis would inevitably follow a fracture across a joint line, the low prevalence of ankle fractures $(5 \%)$ in those $x$-rayed may have favourably influenced the frequency of osteoarthrosis of the ankle in this study.

With the reservation that the effects of age and time have yet to be superimposed on the high frequency of jumping in the sport parachutists, it is concluded that parachutists as a group do not have an increased prevalence of osteoarthrosis of the knee and ankle. In the knee well developed osteoarthrosis seems to be related more to meniscectomy than to parachuting.

We acknowledge the generous help of the British Parachute Association and secretaries of B.P.A. affiliated clubs, the Parachute Regimental Association Leeds and Bradford branches, the Canopy Club, the RAF Sports Parachute Association, the Joint Services Parachute Club, and the many participating parachutists and Military and Civilian radiologists and radiographers. Mrs. B. Gordon and Mrs. J. Battersby gave valuable secretarial assistance.

\section{References}

Adams, I. D. (1973). Osteoarthrosis of the knee joint in sportsmen. M.D. thesis, University of Leeds.

Ahlback, S. (1968). Osteoarthrosis of the knee. A radiographic investigation. Acta Radiologica, Suppl. 277.

Ciccone, R., and Richman, R. M. (1958). The mechanism of injury and distribution of 3000 fractures and dislocations caused by parachute jumping. Journal of Bone and Joint Surgery, 30A, 77-97.

Essex-Lopresti, P. (1946). The hazards of parachuting. British Journal of Surgery, 34, 1-13.

Hearn, P. (1976). Parachutist, 1st ed., p. 65. Hall, London. Jackson, J. P. (1968). Degenerative changes in the knee after meniscectomy. British Medical Journal, 2, 525-527.

Jeffrey, M. R., Kellgren, J. H., and Ball, J. R. (1963). The Epidemiology of Chronic Rheumatism, Vol. II. Atlas of Standard Radiographs of Arthritis. Blackwell, Oxford.

Kellgren, J. R., and Lawrence, J. S. (1958). Osteoarthrosis and disc degeneration in an urban population. Annals of the Rheumatic Diseases, 17, 388-397.

Kiel, F. (1965). Hazards of military parachuting. Military Medicine, 130, 512-521.

Kirby, N. G. (1974). Parachuting injuries. Proceedings of the Royal Society of Medicine, 67, 17-21.

Newnham, M. (1947). Prelude to Glory, p. 5. Sampson Low, Marston, London.

Quinlan, A. G. (1975). Sport parachute injuries. Journal of Bone and Joint Surgery, 57B, 399. 